\title{
Scientists' Preference on Suggested Action Measures and Major Areas of Impact for Changing Weather Patterns in Cuttack District of Odisha, India
}

\author{
Rupashree Senapati*, Prabhat Kumar Singh, Nandini Padhi and Chinmayee Patra
}

M.S. Swaminathan School of Agriculture and School of Fisheries, Centurion University of Technology and Management, Paralakhemundi, Gajapati, Odisha-761211, India

*Corresponding author

K e y w o r d s
Preference, Weather
patterns, Action
Measures,
Patterns
Article Info
Accepted:
$\begin{aligned} & \text { 15 February } 2020 \\ & \text { Available Online: } \\ & 10 \text { March } 2020\end{aligned}$

\section{A B S T R A C T}

A study was conducted for assessing the preference of some suggested measures for changing weather patterns in Cuttack district of Odisha and finding the major areas of impact of and extent of severity amongst five different resources by the scientists of National Rice Research Institute, Cuttack. An appropriate group having adequate understanding on changes in weather conditions was selected and their profile was analysed. Ranking amongst major areas of impact amongst Air and atmosphere, Farming, Sea, Forest and Fresh water Resources was identified by the group. Again suggested actions were given preference and selected by the group according to their importance subsequently. After careful statistical analysis amongst other variables using method of paired comparison and factor analysis, it was found that due to changing weather pattens 'Air and atmosphere' will be most severely damaged followed by Farming activity and others. ICT in Farming, Organic Agriculture, Monitoring and Evaluation of Resources, Developing Knowledge base, Curbing of Pollution etc. gained foremost importance followed by others as important measures here.

\section{Introduction}

Weather occurs primarily due to air pressure, temperature and moisture differences between one place to another. These differences can occur due to the sun angle at any particular spot, which varies by latitude from the tropics. Rising global average temperature is associated with widespread changes in weather patterns. Scientific studies indicate that extreme weather events such as heat waves and large storms are likely to become more frequent or more intense. Weather changes are due to differences in temperature, moisture content and pressure between the atmospheric air masses that circle the planet. Generally speaking, weather is determined by the current state of the atmosphere in a 
particular area, and is also affected by seasonal changes due to the Earth's rotation around the Sun.

Following are some other considered as periodic weather variability like late monsoon onset and more pre- monsoon rainfall, reduced post monsoon and winter rainfall, less rainfall in February, June and October and more number of cloudy days as noticed in Cuttack districts of Odisha. The farming community is affected mostly as the variation in weather also affects different resources of livelihood. If there are some valuable suggestions regarding coping strategies from the experts' opinion, for farming community, it will be of immense help to them.

Variability is concerns of human being. The recurrent droughts and floods in Cuttack in recent past, threaten seriously the livelihood of millions of people who depend on land for most of their needs. The global economy is adversely being influenced very frequently due to extreme events such as droughts and floods, cold and heat waves, forest fires, landslips etc. The natural calamities like earthquakes, tsunamis and volcanic eruptions, though not related to weather disasters, may change chemical composition of the atmosphere.

The damage was more in low-lying areas where cold air settled and remained for a longer time on the ground (Samra et al., 2004). According to Shabalala et al., (2013) Agriculture has both direct and indirect effects on the leading causes of water quality degradation, mainly as a result of the excessive use of agrochemicals. Seasonal patterns in the concentration of physicochemical variables occur, as land use, rainfall and farming activities change seasonally, and these concentrations should therefore be determined periodically.
Understanding the weather changes over a period of time and adjusting the management practices towards achieving better harvest are challenges to the growth of agricultural sector as a whole. The climate sensitivity of agriculture is uncertain, as there is regional variation in rainfall, temperature, crops and cropping systems, soils and management practices. The inter-annual variations in temperature and precipitation were much higher than the predicted changes in temperature and precipitation. The crop losses may increase if the predicted climate change increases the climate variability.

\section{Need for the study}

Odisha is experiencing distinctive changes in climatic pattern. Atmospheric temperature is going up in the state making the summer seasons almost unbearable. Low pressure is becoming a regular phenomenon causing an unpredictable rainfall pattern across the state. Once proud to have a little over 480 kilometers long coastline, people of Odisha now see it as a danger. Therefore coastal districts are more prone to climate change chaos and the experienced local peoples' perceptions can be studied for further investigation. For micro level, the study starts off from chosen districts to the block or village periphery. Therefore Cuttack district has been purposively selected as it is prone to get danger from seasonal variability with all the above mentioned resources of livelihood are getting adversely effected and consumed by a huge farming community.

\section{Objectives}

Keeping in view the importance of climate change and ongoing studies at various levels, the following objectives were taken under study.

1. To identify the study group amongst scientists with their socio-educational 
background.

2. To identify the major resource areas which would be most adversely affected due to changing weather patterns as perceived by the group on five selected major areas viz. Air and atmosphere, Farming Sector, Sea , Forest and Fresh water Resources .

3. To identify some important action measures as perceived by scientists of NRRI for ameliorating the adverse effect of regarding changing weather patterns in Cuttack district of Odisha.

\section{Materials and Methods}

Scientists are considered very objective and have high level of awareness on changing weather patterns, therefore it was felt very rational to take the agricultural scientists as respondents for the study. Many scientists also have undertaken projects related to the concerned topic. Therefore Scientists' perception was considered more correct than other groups.

In consultation with the scientists many areas affected by periodic weather changes were listed and major areas were identified. Based on the objectives a questionnaire was developed. The data have been collected by questionnaire method. Since the scientists of NRRI were more occupied, a draft questionnaire was prepared and pre-tested by the faculties and experts of BCKV Agriculture University for selection of appropriate variables for the study. The data have been analyzed in factor analysis. There were 77 no. of scientists working under different disciplines of NRRI, therefore instead of adopting sampling method total enumeration was followed.

In the present investigation all the variables selected were independent variables and therefore cause and effect relationship was not found out. The projected impact of seasonal variation is likely to affect the following major components.

Air and atmosphere

Farming Sector

Sea

Fresh water resources

Forest

For this purpose the selected five areas were presented to scientists in pairs in ten possible combinations. The statistical methods used were method of paired comparison, frequency and percentage.

\section{Scaling through paired comparison}

Thurston (1929) developed the law of comparative judgment, which provides rationale for the order for the ordering of stimuli along a psychological continuum. It is a psychological scaling method and makes possible the quantitative investigation of all kinds of values and experiences, Edwards (1953). In this method, the areas of major impact (items, statements or variables as stimuli) are presented in pairs in all possible combinations and the respondents asked to select one pair over the other from each pair, which is judged as more favorable.

\section{Extraction of factors through factor analysis}

Further investigation was intended to find out some action measures for reducing the adverse effects of changing weather in Cuttack district. For this more than 50 activities were selected from diversified trustworthy sources. After discussion with the scientists of agricultural universities 35 activities or measures have been identified to judge the importance of items or activities for reducing the adverse weather impacts. All these 35 items have been provided with a three point continuum - most important, 
important and not so important with weights of 3, 2 and 1 respectively. The scoring of each item was summed up and the items i.e. the action measures were ranked on the basis of total rank score. Then the data were used for factor analysis.

Factor is a hypothetical construct/ classification. There may be one/more factors depending upon the nature of study and number of variables involved in it. Factor analysis is used to study the relationship among many dependent variables, with the goal of discovering something about the nature of independent variables that affect them even though those independent variables were not measured directly. Thus answers obtained by factor analysis are necessarily more hypothetical and tentative than is true when independent variables are observed directly. The inferred independent variables are called factors.

Factor loadings are those values which explain how closely the variables are related to each one of the factors discovered. Then through principal component analysis eigenvectors are obtained. The principle components are then converted into factors. Factors thus besides the direction also represent the variances. Here the no. of factors extracted by principal component method is 1 .

\section{Results and Discussion}

\section{Profile of NRRI Scientists}

As shown in the table-1 $40 \%$ scientists belong to middle aged group and about 32\% scientists are older in age. Only one fourth scientists are younger in age. During the collection of data there were 77 scientists available at work station. In case of educational background $50 \%$ scientists were having doctoral degree and 50\% scientists were possessing post graduate degree as their qualification. The table indicates that $10 \%$ scientists were in service experience up to fifteen years. The number of scientists possessing more than 15 years work experience was $40 \% .10 \%$ scientists were in service experience up to 10 years and other $40 \%$ scientists were having at least up to 5 years experience. Therefore the group consisted of scientists from multiple disciplines with diversified experiences making this a suitable group for this a study.

\section{Major areas of impact of climate change}

Z-Matrix depicts that the Air and atmosphere has got the highest scale value (0.798) and component and scale value Farming Activity was 0.758 . The scientists of NRRI perceived that due to differing weather patterns the Air and atmosphere and Farming resources will be affected the most. The other resources viz. Sea , Forest and Fresh water resources will also be affected as these have received lower scale value.

\section{Important action measures}

The analysis calls for selection of a minimum number of meaningful and useful factors, considerably fewer in number than the original variables which will convey for most of the variances in the data set. Various criteria for election of suitable factors are available. Kaiser (1958) and others have recommended retaining all those Eigen values which have value more than 1. Scanning through each factor column for large absolute values in the varimax matrix (Kaiser) will reveal a few variables with significantly high factor loadings and many others with insignificant loadings. Fairly high communality of each variable implies the appropriateness of the model adopted for the study. The last step involved meaningful interpretation of factors. 
For interpretation of factors, variables with high factor loadings ignoring the sign (+ve/ve) were taken into consideration. In the present investigation variables with factor loading 0.600 or above we have selected others with negligible values were omitted or merged with the selected twelve action measures as perceived by the scientists as per the statistical analysis with high factor loadings. They are also ranked sequentially according to their perceived importance as obtained from the study.

Table.1 Profile of National 1 Rice Research Institute scientists

\begin{tabular}{|l|l|c|c|}
\hline Items & Category & Frequency & Percentage (\%) \\
\hline Age & Young (up to 35 years of age) & 11 & 27.50 \\
\cline { 2 - 4 } & Medium Age (35-50 years of age) & 16 & 40 \\
\cline { 2 - 4 } & Old (51 years and above) & 13 & 32.5 \\
\hline \multirow{5}{*}{ Education } & PhD & 20 & 50 \\
\hline \multirow{3}{*}{$\begin{array}{l}\text { Field Specialisation } \\
\text { M.Sc. }\end{array}$} & Crop Improvement Division & 20 & 50 \\
\cline { 2 - 4 } & Crop Production Division & 9 & 22.50 \\
\cline { 2 - 4 } & Crop Protection Division & 9 & 22.50 \\
\cline { 2 - 4 } & Biochemistry, Physiology and & 8 & 22.50 \\
\hline \multirow{5}{*}{ Work Experience } & Environmental Sciences (BPES) & & \\
\cline { 2 - 4 } & Social Science Division & 5 & 12.5 \\
\hline & Upto 5 years & 16 & 40 \\
\hline & Upto 10 years & 4 & 10 \\
\cline { 2 - 4 } & Upto 15 years & 16 & 10 \\
\cline { 2 - 4 } & More than 15 years & & 40 \\
\hline
\end{tabular}

Table.2 Ranking of components on the basis of severity of damage due to climate change Z-Matrix

\begin{tabular}{|c|c|c|c|c|c|}
\hline & Forest (d) & $\begin{array}{l}\text { Fresh water } \\
\text { resources(e) }\end{array}$ & Sea zone(c)) & Farming Sector (b) & $\begin{array}{l}\text { Air and atmosphere } \\
\text { (a) }\end{array}$ \\
\hline Forest and wildlife(d) & 0.000 & 0.038 & 0.429 & 1.335 & 0.604 \\
\hline Hydrology and water resources(e) & -0.040 & 0.000 & -0.192 & 0.429 & 0.189 \\
\hline Coastal zone(c)) & -0.432 & 0.189 & 0.000 & -0.040 & 0.429 \\
\hline Agriculture and allied(b) & -1.341 & -0.432 & 0.038 & 0.000 & 0.348 \\
\hline Environment(a) & -0.607 & -0.192 & -0.432 & -0.350 & 0.000 \\
\hline SUM & -2.420 & -0.397 & -0.157 & 1.374 & 1.570 \\
\hline MEAN & -0.484 & -0.079 & -0.031 & 0.274 & 0.314 \\
\hline $\begin{array}{l}\text { Add largest negative deviation with } \\
\text { positive sign }\end{array}$ & 0.484 & 0.484 & 0.484 & 0.484 & 0.484 \\
\hline RANK(Scale value) & $\begin{array}{l}0.000 \\
(5 \text { th })\end{array}$ & $\begin{array}{l}0.408 \\
(4 t h)\end{array}$ & $\begin{array}{l}0.453 \\
(3 r d)\end{array}$ & $\begin{array}{l}0.758 \\
(2 n d)\end{array}$ & $\begin{array}{l}0.798 \\
(1 \mathrm{st})\end{array}$ \\
\hline
\end{tabular}


Table.3 List of suggested action measures

\begin{tabular}{|c|c|c|c|}
\hline $\begin{array}{l}\text { Sl.n } \\
\text { o }\end{array}$ & Action Programme & $\begin{array}{l}\text { Sl.n } \\
\text { o. }\end{array}$ & Action Programme \\
\hline 1 & Developing HYV crops needing less water & 19 & Preventing forest fire and charcoal making \\
\hline 2 & $\begin{array}{l}\text { Developing crop varieties to withstand some water stress and high } \\
\text { temperature }\end{array}$ & 20 & Preventing forest fire and charcoal making \\
\hline 3 & Altering dates of planting/ sowing, spacing & 21 & Protection and regeneration of mangroves in delta areas and sea sides \\
\hline 4 & Adopting mixed cropping and crop livestock mixed farming & 22 & Regulating level of pollution in all manufacturing industries \\
\hline 5 & Practicing minimum tillage or zero tillage & 23 & Control use of non-renewable sources of energy like coal, petrol etc \\
\hline 6 & Soil and water conservation & 24 & Continuous monitoring of pollution levels of air, river and sea water \\
\hline 7 & Facilitating ground water recharging & 25 & $\begin{array}{l}\text { Strict enforcement of laws relating to forest, environment and pollution } \\
\text { control }\end{array}$ \\
\hline 8 & $\begin{array}{l}\text { Regulation lifting of ground water for farming commercial and domestic } \\
\text { purpose }\end{array}$ & 26 & $\begin{array}{l}\text { Improving quality of meteorological information and their quicker and } \\
\text { rapid dissemination }\end{array}$ \\
\hline 9 & Enhancing storage and use of rain water & 27 & Raising awareness of people about global warming and climate change \\
\hline 10 & Bringing more areas and crops under drip and sprinkler irrigation & 28 & Changing cropping pattern \\
\hline 11 & Less use of synthetic fertilizers and pesticides & 29 & $\begin{array}{l}\text { Intensive bamboo cultivation which can absorb oxides of nitrogen and } \\
\text { carbon }\end{array}$ \\
\hline 12 & More use of natural fertilizers and pesticides & 30 & $\begin{array}{l}\text { Application of remote sensing techniques, GIS and crop simulation } \\
\text { models }\end{array}$ \\
\hline 13 & Bringing more areas and more crops under organic farming & 31 & Promotion of eco-tourism \\
\hline 14 & Rationalized cutting of trees and forest plants & 32 & Short, medium, long term weather forecasts \\
\hline 15 & Integrated water resource management & 33 & Manipulating crop micro-climate \\
\hline 16 & Promoting agri-business insurance & 34 & Use of multipurpose adopted livestock species and breeds \\
\hline 17 & $\begin{array}{l}\text { Establishing network of village knowledge centre with internet and satellite } \\
\text { connectivity for early warning }\end{array}$ & 35 & Introduction of weather insurance (heat, cyclone, lightening) \\
\hline 18 & Introduction of climate field schools & & \\
\hline
\end{tabular}


Table.4 List of action programme (12 factors) after factor analysis (Total percentage variance was explained by the 12 factors $=81.95 \%$ )

\begin{tabular}{|c|c|c|c|}
\hline Factors & Variables with factor loading & Variance & Factor Renaming \\
\hline Factor 1 & $\begin{array}{l}\text { X30 }=0.850 \\
\text { Establishing network of village knowledge centre with internet and satellite connectivity for early warning on storm, cyclone } \\
\text { X35 }=0.682 \\
\text { Use of multipurpose adopted livestock species and breeds } \\
\text { X26=0.643 } \\
\text { Application of remote sensing techniques, application of GIS, application and development of crop simulation model }\end{array}$ & $10.84 \%$ & ICT in Farming \\
\hline Factor 2 & $\begin{array}{l}\text { X11 Less use of synthetic fertilizer and pesticides } \\
\text { X12 More use of natural fertilizers and pesticides }\end{array}$ & $9.06 \%$ & Organic Agriculture \\
\hline Factor 3 & $\begin{array}{l}\text { X23 } \\
\text { Raising awareness of people about global warming and climate change } \\
\text { X19 } \\
\text { Increasing the use of renewable sources like solar energy, wind energy etc }\end{array}$ & $7.66 \%$ & Developing Knowledge base \\
\hline Factor 4 & $\begin{array}{l}\mathrm{X} 25=0.808 \\
\text { Intensive bamboo cultivation which can absorb oxides of nitrogen in addition to } \mathrm{CO} 2 \\
\mathrm{X} 20=0.686 \\
\text { Continuous monitoring of pollution levels of air, river and sea water } \\
\text { X13=0.680 } \\
\text { Bringing more areas and more crops under organic farming }\end{array}$ & $7.6 \%$ & $\begin{array}{l}\text { Monitoring and Evaluation } \\
\text { of Resources }\end{array}$ \\
\hline Factor 5 & $\begin{array}{l}\text { X17 }=0.887 \\
\text { Regulating level of pollution in all manufacturing industries (big / small / rural / urban) } \\
\text { X32= } 0.648 \\
\text { Short, medium, long-term weather forecast for reducing production risk. }\end{array}$ & $6.699 \%$ & $\begin{array}{l}\text { Pollution control and } \\
\text { weather forecasting }\end{array}$ \\
\hline Factor 6 & $\begin{array}{l}\mathrm{X} 22=0.907 \\
\text { Improving quality of meteorological information and their quicker and rapid dissemination }\end{array}$ & $6.691 \%$ & $\begin{array}{l}\text { Dissemination of } \\
\text { meteorological information }\end{array}$ \\
\hline Factor 7 & $\begin{array}{l}\mathrm{X} 5=0.620 \\
\text { Practising minimum tillage or zero tillage where applicable } \\
\mathrm{X} 6=0.714 \\
\text { Soil and water conservation }\end{array}$ & $6.65 \%$ & Conservation practices \\
\hline Factor 8 & $\begin{array}{l}\mathrm{X} 3=0.825 \\
\text { Altering dates of planting/sowing, spacing and input management } \\
\mathrm{X} 24=0.764 \\
\text { Changing cropping pattern }\end{array}$ & $6.20 \%$ & Changing cropping pattern \\
\hline Factor 9 & $\begin{array}{l}\mathrm{X} 1=0.744 \\
\text { Developing } \mathrm{HYV} \text { crops which requires less water } \\
\mathrm{X} 9=0.728 \\
\text { Enhancing storage and use of rain water }\end{array}$ & $5.62 \%$ & Water management \\
\hline Factor 10 & $\begin{array}{l}\mathrm{X} 31=0.680 \\
\text { Shelter belts and natural management }\end{array}$ & $5.50 \%$ & $\begin{array}{l}\text { Protection of Resources } \\
\text { through different means }\end{array}$ \\
\hline Factor 11 & $\begin{array}{l}\mathrm{X} 15=0.892 \\
\text { Preventing forest fire and charcoal making } \\
\text { X14=0.613 } \\
\text { Rationalized felling of trees and forest plants }\end{array}$ & $5.00 \%$ & $\begin{array}{l}\text { Rationalization of eco } \\
\text { friendly inputs }\end{array}$ \\
\hline Factor 12 & $\begin{array}{l}\mathrm{X} 2=0.719 \\
\text { Developing crop varieties which can withstand some water stress and high temperature }\end{array}$ & & $\begin{array}{l}\text { Promotion of stress resistant } \\
\text { varieties }\end{array}$ \\
\hline
\end{tabular}


The action programmed derived from 12 factors are presented below according to their importance.

1. ICT in Farming

2. Organic Agriculture

3. Developing Knowledge base

4. Monitoring and Evaluation of Resource

5. Pollution control and weather forecasting

6. Dissemination of meteorological information

7. Conservation of Resources

8. Management of Soil and Air Pollutant

9. Water management

10. Knowledge management

11. Rationalization of consumption of resources

12. Promotion of eco-friendly inputs

In conclusion, the given study and graph represents that the Air and atmosphere has got the highest scale value and scale value of Farming was next to it and almost approaching each other to some extent. It seems that if alteration in Air or atmospheric gases (Carbon dioxide, Carbon monoxide, Oxygen etc.) occurs then it may directly affect the agricultural and allied sector as atmospheric gases take part in photosynthetic and other physiological activities of plants. The next vulnerable areas will be Fresh water resources with 0.453 scale value and Sea zone with 0.403 scale value. Both these areas have nearly equal severity which indicates that those will be affected relating to atmospheric pressure, temperature, oceanic movements etc. The scale value of Forest has been made to zero for comparative statistical analysis though not absolute zero and it does not indicate that Forest would not be affected change in weather phenomenon but it will be the least severely affected area amongst the five selected areas though also vulnerable to some extent according to scientists' perception. It may be due to the forest ecology maintains a natural balance through the presence of diversified flora and fauna and their physiological activities.

Regarding the suggested measures, ICT in Farming has become the most important factor as expected because of rapid communication, information dissemination and awareness development amongst rural mass especially in coastal zone. The Organic Agriculture, Developing knowledge base etc were also very important according to scientists. Natural resource monitoring and pollution control strategies are necessary for long-term goals. Next issue has been the dissemination of meteorological information and in coastal areas it will be of vital importance. In farm conditions need for conservation of practices (soil and water, minimum tillage) and water management ( ground water recharging, developing water stress resistant varieties etc) are required to face the changes in weather pattern. Knowledge management of farmers is definitely an important step forward in this approach though it is ranked quite low here. And last but not the least we have to save trees and go green to mitigate the effects to some extent.

The above factors as perceived by the scientists may be considered for deciding ,implementing and evaluating the short term and long term projects, schemes and events where ameliorating the adverse weather effects for coastal villagers would have been the core objectives. Further studies in this and allied areas will also enhance the scope for awareness, knowledge and motivation.

\section{Acknowledgement}

I owe my deep acknowledgement to Dr Sagar Mondal, Associate Professor, B.C.K.V., and my mentor for his kind cooperation. 
I am very much grateful to Dr. T. K. Adhya, the then Director of CRRI who gave me permission to collect data from the scientists. I give my heartfelt thanks to all the scientists of NRRI who despite of their busy schedule took interest in this questionnaire and gave cooperation. And last but not the least, I owe my deep respect to Dr B.N. Sadangi, the then HOD, Social Science Division and my Project Investigator afterwards for his guidance in every aspect without whom this work could have never been possible.

\section{References}

Samra, J.S., Singh, G and Ramakrishna, Y.S. (2004) Cold wave during 2002-03 over North India and its effect on crops. The Hindu dated 10th January, 2004. p. 6.

IPCC (Intergovernmental Panel on Climatic Change) 2006. The Economics of Climate Change: Stern Review. The Summary of conclusions. Survey of the Environment 2007, The Hindu, pp141145. IPCC (Intergovernmental Panel on Climatic Change) 2007. Climate Change: The Physical Science Basis. Extracts from the IV Assessment Report. Survey of the Environment 2007, The Hindu, pp147-155

Climate change and its Impact on Agriculture (MANAGE Report)

Adjei Nsiah, S., Issaka, R. N., Fenning, J. O., Mapfumo, P., Anchirina, V., and Giller, K. E. (2010) Farmers' perception on climate change and variability and existing opportunities for adaptation in Wenchi area of Ghana. International Journal of Climate Change: Impacts and Responses. 2(2): 49-60

Belanger, D., Gosselin, P., Valois, P., Germain, S., and Abdous, B. (2009). Use of a remote car starter in relation to smog and climate change perceptions: a population survey in Quebec(Canada). International Journal of Environmental
Research and Public Health 6(2): 694709

McKinnon, G. A., and Webber, S. L. (2005) Climate change and forestry. Forestry Chronicle, 81 (5): 653-716

Shackley, S., and Deanwood, R. (2002) Stakeholder perceptions of climate change impacts at the regional scale: implications for the effectiveness of regional and local responses. Journal of Environmental Planning and Management. 45(3): 381-402

Williamson, T. B., Parkins, J.R., and McFarlane, B. L. (2005) Perceptions of climate change risk to forest ecosystems and forest-based communities. Forestry-Chronicle 81(5): 710-716

Wyborn, C. (2009) Managing change or changing management: climate change and human use in Kosciuszko National Park. Australasian Journal of Environmental Management 16(4): 208217

Shabalala, A. N., Ludwig Combrinck; Robert McCrindle. Effect of farming activities on seasonal variation of water quality of Bonsma Dam, KwaZulu-Nat2013 South African Journal of Science vol.109 n.78 Pretoria Jan. 2013

Edwards, A. (1953) Personal Preference Schedule, Manual. New York: Psychological Corp., Measures needs in a forced- choice (pair comparison) format; used a great deal.

Thurstone, L., and Chave, E., (1929) The Measurement of Attitude. Chicago: University of Chicago Press.

Senapati, R., Biswas. R., Mondal, S., (2017) Perception of Coastal Odisha Experienced Farmers on Seasonal Variations International Journal of Agriculture Innovations and Research, Vol. 5, Issue 6, ISSN (Online) 23191473. 


\section{How to cite this article:}

Rupashree Senapati, Prabhat Kumar Singh, Nandini Padhi and Chinmayee Patra. 2020. Scientists' Preference on Suggested Action Measures and Major Areas of Impact for Changing Weather Patterns in Cuttack District of Odisha. Int.J.Curr.Microbiol.App.Sci. 9(03): 23992408. doi: https://doi.org/10.20546/ijcmas.2020.903.274 